\title{
RENEWAL OF DESIGN TEACHING RESOURCES BY THE PRACTICE OF ENVIRONMENTAL SCANNING
}

\author{
Roumy Akue, Magali \\ Paris-Descartes University
}

\begin{abstract}
Teachers' resources renewal is a critical aspect of design education. Design teachers update and renew their resources to keep their lectures and project topics up to date, in line with contemporary issues and societal changes, and to assure their lifelong learning and professional development. Yet, few studies were published on resource renewal process in design education. Researches usually focus on teaching resources and cultural capital qualification. This paper analyses the resource renewal process in design education. Our methodology comprehends the construction of a conceptual framework based on Environmental Scanning, which was studied through a qualitative study involving fifteen design teachers in France. Our results show that design teachers update and renew teaching resources according to their personal areas of interest and students' needs. Their renewal process is different depending on whether they are creating lectures and topics, they are working with other teachers or with external partners. Relationships and networks appear important, teachers rely on their network of colleagues, design practitioners and project partners to access emerging issues.
\end{abstract}

Keywords: Design education, Life-long learning, Knowledge management

\section{Contact:}

Roumy Akue, Magali

Paris-Descartes University

Education Sciences

France

magali.roumy@gmail.com

Cite this article: Roumy Akue, M. (2019) 'Renewal of Design Teaching Resources by the Practice of Environmental Scanning', in Proceedings of the 22nd International Conference on Engineering Design (ICED19), Delft, The Netherlands, 5-8 August 2019. DOI:10.1017/dsi.2019.60 


\section{BACKGROUND AND OBJECTIVE}

This paper focuses on the process of teaching resource update and renewal in design education. By renewal, we mean a sustained and recurring activity of updating resources over time. We use "design" in two different meanings, design oriented towards artefact conception and design oriented towards educational device conception. We distinguish internal resources and external resources. Internal resources are personal to the teacher and rely on individual characteristics such as inner strength. External resources are shareable materials updated by the teaching practice (Loffreda \& Bruillard, 2017). This paper focuses on external resources.

In design, resources are considered critical to enable creativity and innovation (Huber, 1998; Ashton, 2007; Goncalves, Cardoso \& Badke-Schaub, 2014). Indeed, design addresses human activities that are constantly evolving (Archer et al., 1992) in complex environments (Broadbent \& Cross, 2003). Teachers have to understand those evolutions to take into account societal emerging issues, to open their mind to design opportunities and to enculture students (Strickfaden, 2007).

In this context, teaching resources serve the identification of emerging trends (Geel, 2010, p. 32) necessary to define a "problem statement" and a "design brief" (Chen, 2016). They also nourish teachers' contributions and feedback (Demirbas \& Demrikan, 2007) during design studio lessons. Teachers must renew their resources to cope with the changing nature of design incentives and students' singular needs.

Related work in design education addresses a close concept to teaching resources that is design references. References refer to educational material for inspiration (Debs \& Kelley, 2015) shared in the conception environment (Strickfaden et al., 2006). They include artefacts, documents, books, drawings and personal experiences on which teachers and students rely (Strickfaden et al., 2006). References are used during the design teaching process (Strickfaden \& Rogers, 2007). These works focus on reference qualification and on teachers cultural capital to enculture students (Strickfaden \& Heylighen, 2007). Even though they identify renewal factors, these works are not primarily oriented towards resources renewal processes.

Outside design education, few works study teachers' resources. They generally focus on teaching resource selection, collection and transformation. However, these works cannot be applied as-is to design education, teaching resources and their management are specific to teaching courses (ReVEA, 2015).

Requirements for resource update and renewal bear some similarities with the environmental scanning processes studied in management science. Indeed, both respond to the imperative of resource and information update regarding a changing context.

In environmental scanning, organizations scan their external environment in order to identify new trends, signals and change patterns so as to forecast the future (Morrisson, 1992). Articulated with "internal analysis" (Morrisson, 1992, p.88) oriented toward internal choices and vision, environmental scanning allows decision-makers to make decisions about the future. Environmental scanning is a key process enabling adaptation to evolution in complex environments.

Harnessing those similarities, we built a conceptual framework based on environmental scanning that we adapted to design education.

In the next section, we present the environmental scanning framework and how we adapted it to design education. We describe its process and key concepts.

In the third and fourth section, we present how our custom-made framework was used through a qualitative analysis with a sample of fifteen French teachers coming from different design backgrounds and fields and teaching at different post-graduate levels.

Our results contribute to the understanding of design teachers' resource renewal processes in order to improve the training of future design teachers and practitioners, and their resource updating processes.

\section{ENVIRONNMENTAL SCANNING CONCEPTUAL FRAMEWORK}

In this section, we show how we built our conceptual framework to characterize the process of resource renewal. We selected key parts of environmental scanning theories that could ensure a strong analysis tool to understand resource renewal in design education. The framework combines the concepts of scanning areas, modes and organizations. 


\subsection{Environmental scanning definition}

Environmental scanning is "a kind of radar to scan the world systematically and signal the new, the unexpected, the major and the minor" (Wiener \& Brown, 1985, p.IX). Many papers address the question of identifying signals (Yoo \& Sawyerr 2014), environmental turbulences (Haase et al., 2011), uncertainties (Daft, Sormunen \& Parks 1988; Haase et al., 2011) or discontinuities (Fahey et al., 1981). During the process, organizations collect information "about events, trends, and relationships in an organization's external environment, the knowledge of which would assist the management in planning the organization's future course of action." (Bhardwaj \& Kumar, 2014, p.40).

Different scanning modes have been observed and theorized. They take place in scanning areas comprising environment, sources and information. The pace of acquisition, the individual and collective planning and organization and networking are also part of the resource renewal device.

\subsection{Environmental scanning area}

The scanning area is characterized by the environment, meaning the broad context of interest, and sources that can be considered as filters through which the noise of the environment is separated from the relevant information.

\subsubsection{Environmental scanning environment}

The structure of the environment is mainly described as external (Duncan, 1972). It can be divided into macro-environment, mezzo-environment and micro-environment scales according to its indirect or direct influence on the organization.

At the macro scale, the influence of the environment is indirect. The environment can be divided into social, political, technological and economic realms (Jain, 1984).

At the mezzo scale, the environment is divided in general and activity related sectors (Choo, 1999; Hambrick, 1982; Yoo \& Sawyerr, 2014). The activity sector is important to monitor because of its great influence on the organization activities.

At the micro scale, there are direct and daily transactions between the environment and the organization. The environment has a direct influence on the organization (Daft et al., 1988).

Daft, Sormunen and Parks (1988) similarly characterize the environment as macro and micro, talking about outer and inner layers. The outer layer indirectly impacts the organization, the inner layers include customers, suppliers that interact regularly with the organization thus directly impact the organization.

\subsubsection{Environmental scanning sources}

The environment is influenced by evolving trends (Saywerr, 1993; Albright, 2004) that need to be identified for optimal scanning efficiency. Scanning analysts use sources to access these trends. Sources are at the same time, the origins of information and the filters that reduce the information retrieval area (Hurtado, 2014).

Sources can be internal or external to the organization, personal or impersonal, documentary or human. Personal sources are gathered intentionally for a specific person, impersonal information is not intended to the scanning analyst.

Documentary sources for example, consist of prospectuses and annual reports while human sources include any person who can supply information (Yoo \& Sawyerr 2014). Finally, sources can be offline and online (Keegan, 1974; Yoo \& Sawyerr 2014; Hiltunen 2008).

The quality of sources is a matter of importance. A high-quality level induces reliability, accuracy and objectivity, a fast access to information, a high-frequency update at an acceptable cost for the organization (Smith et al., 2010). Hiltunen (2008) shows that some sources are efficient regardless of the domain, while others are considered to be highly specialized. Moreover, their selection may be influenced by more emotional and social factors, such as the popularity of the source (Robinson \& Simmons, 2017), and the image of the source can affect their selection or exclusion.

\subsubsection{Environmental scanning information}

Information is the purpose of the scanning processes. It is not about gathering information exponentially, but rather identifying key information that reveals future trends. Scanning analysts have 
to identify in the environment, sources providing weak signals (Ansoff, 1984; Hiltunen, 2006), fresh information (Deiss, 2015) and grey information (Schöpfel, 2015).

A weak signal is an emerging information, ranging from the vaguest to the clearest. "Weak signals are defined here as seemingly random or disconnected pieces of information that at first appear to be background noise, but which can be recognized as part of a larger pattern when viewed through a different frame or by connecting it with other pieces of information" (Schoemaker et al., 2013, p 815). The freshness of the information (Deiss, 2015) is another essential parameter of consideration. It concerns both the source and the information itself. The freshness of the information is characterized by its recency of publication. Its relevance and value are defined by its credibility and its wealth, and are linked to its updating (Boya, 2010).

Grey information is legally accessible but difficult to access practically. The added value of the grey information is related to its freshness, its abundance and its closeness to the field realities (Schöpfel, 2015).

\subsection{Environmental scanning modes}

Choo (1999, p.22) identifies four type of scanning modes, two viewing modes that include "undirect viewing" and "conditioned viewing" and two "searching" modes that include "informal searching" and "formal searching".

"Undirect viewing" consists of detecting changes as early as possible using varied sources. A large amount of coarse grain information is monitored and filtered to identify areas of interest.

In "conditioned viewing", the individual explores selected issues in order to assess the importance and impact of the information on the organization. The number of sources is limited as well as the time and the effort of scanning.

In "informal search", the individual seeks in-depth information to understand a specific problem to acquire knowledge with a limited monitoring effort. If the individual identifies a higher need, he will dedicate more time to his research.

In "formal search", the individual plans and deploys organized efforts to obtain accurate information related to a given problem with a fine granularity of information.

\subsection{Environmental scanning organization}

The environmental scanning process can also be characterized by its organization, that is the monitoring pace and frequency, planning strategies and networking usage.

The pace and planning of monitoring are important parameters for renewal. A high mastery level sustains the scale and the durability of valuable information renewal.

Pace refers to the repeat rate of environmental scanning and planning to the programming of the scanning activity. Fahey et al. (1981) characterized different planning process mastery levels as "irregular", "periodic" and "continuous" scanning frequencies, more or less planned. According to them, "irregular" scanning is linked to exceptional crisis events, "periodic" scanning focuses on medium term problem solving and "continuous" monitoring is geared towards long-term opportunities. Long-range planning combines "planning time", "staffing or planning committees" and the production of "planning documents" as well as "timetable of planning" (Javidan, 1984, p. 386).

Relationships and networks are also a source of information and play an important part of the scanning organization. Monitoring sharing in an "attentional network" (Amabile, 1999) appears as a solution to increase acquisitions. "Voluntary networks" and multidisciplinary networks (Schoemaker \& Day, 2012) or "weak links" (Granovetter, 1973, Breillat, 2011) can provide rich and unexpected information. Networking facilitates identification of emerging topics and salient events.

During our work, we analysed all those parameters to identify the main elements of teachers' resource renewal processes. They are presented in the following section.

\section{COLLECTION AND ANALYSES OF RENEWAL}

We used a qualitative approach to understand the processes of resource renewal. The results were obtained through semi-structured interviews with fifteen teachers of different levels of experience. We conducted an inter-site study (Miles \& Huberman, 1991) on five postgraduate groups from three different schools. We used an interview guide to assess the motivations for resource renewal, the pace of acquisition and the interaction dynamics within the teams. 
The teachers came from different areas and design fields, product and graphic design, transversal design, and social design. The sample includes teachers, some of whom are also design practitioners or researchers. Teachers were in a position to share and explain their context, their motivations for resource renewal, the contents of their resources, the selection of sources, the acquisition of information and the organizational modes in their networks.

For coding, we proceeded by "inductive-hypothetic-deductive" loop (Huberman \& Miles, 1991) with a round trip between the interview corpus and the conceptual model (Paquay, 2006). We analysed our data at two scales, the individual scale and the collective scale.

\section{RESULTS}

\subsection{Renewal triggers: topic conception and students support}

Resources are mainly renewed for design teaching situations. Two situations trigger renewal: the design of "topics" and the pedagogical support of students.

- The design of "topics": topics are formalized by teachers in a document and define the creative incentives, the form of design boards, the references, the schedule and the evaluation criteria. Teachers renew creative incentives, work contexts and resources that can be internet links, books titles, videos or artefacts.

Tristan: "I give them documents with problems, texts, things like that. It's also to them too to complete with their research"

- The pedagogical support of students in the design process: the pedagogical support includes the identification of topics during the definition of graduation works and projects. Teachers analyse students' needs and provide additional resources.

The feedback takes place during verbal exchanges and written communications on thesis works and design project boards.

Gwennaelle: "We build a foundation for reflection for each student. It's personalized to each student."

Gwennaelle: "The teachers accompany students. [...]. We can also bring references that the students have missed, bibliographical references, cultural and artistic references"

Teachers renew their resources in line with students' needs. This drives teachers to undertake complementary research to bring adapted answers, whether they are creative incentives or material resources.

\subsection{Renewal areas: a balance between teachers and stakeholders' areas}

Concerning design topics for design studio, we identify topics defined by teachers or arising from external stakeholders.

For design topics defined by teachers, they formalize the scenarios and the settings of assignments. They use their own resources to define specific topics. They are sometimes engaged in collaborative topic writing with colleagues and/or partners. This has an impact on teachers' resource area. In this case, the backgrounds and fields of knowledge cross the environmental scanning areas of all the actors. Colleagues and partners propose creative incentives, methods, and resources. This leads all stakeholders to learn about other areas of interest.

Johann: "it's not a carte blanche that we give them, it's not a specification that we provide them either, it's really, we actually design the workshops in a partnership logic, so in fact we co-build something by trying to do the best with the skills of everyone."

Sometimes, teachers give partners carte blanche to define topics. This leads teachers to learn about external partners resource areas. At the same time, this gives students access to other fields.

Yohan: "with an external actor designer, we said [...] you have carte blanche, what methodology to you want to use?"

We identify two resource areas: teachers' resources selected in their own area and partners' resources that help broaden the spectrum of teacher's resources.

Teachers also seek sponsors and contests to propose project topics defined by external stakeholders. Their first goal is to spot important people, contests opportunities or external partners.

Johann: "so this year we did two topics, one of them was really basic, a contest on copper." 
Yohan: "Situations [...], very concrete, that rely on sponsors committees that can be very restrictive projects [...]."

Those situations require constant monitoring of resources that are partners, contests, or sponsors. This monitoring is continuous for each new project.

\subsection{Beyond the viewing and searching scanning modes}

Although, we observe both viewing and searching modes defined in section 2.3, we discover two additional types of environmental scanning. We identify a self-centred monitoring based on the teacher's own interests, more oriented towards the design of topics and a student-centred monitoring oriented towards each student's problems.

In the self-centred monitoring, teachers confirm monitoring recurrent areas. For example, Gwennaelle studies field forces linked to politician and political organizations. Renaud says that he particularly explores problems around the invisible, the unmistakable, the immeasurable, the un-representable and the archived. A third teacher, Samy investigates primary forms of civilization, industry and poverty. Teachers deepen their own areas of interest over a long-time and accumulate resources over time.

In student-centred monitoring, teachers initiate an ex-post research focused on students' needs.

Johann: "it happens I search something when I miss something."

Sometimes, they plan their acquisition ahead. They acquire and store resources in a database that can be used during the lessons.

Elisa: "About knowledge, I am so organized. Because, it is the only way I find to have an available knowledge base I could use in improvisation with students and also to make archives when I prepare my topics."

The acquisition is sometimes outsourced to students through given exercises. It is a kind of formal search with externalization of scanning activity.

Johann: "They bring me 90 references per year, very specific. they bring me an average of 120 references per year with a full description. We analyze them together, etc. [...], you hold them back, you memorize them."

Teachers in this case renew their resources in foreign and less known fields.

\subsection{Preferential sources and reciprocal scanning}

The usage of sources responds to a number of habits. Teachers show recurring methods and channels to access resources that we call preferential sources.

Teachers have habits regarding consultation methods and consulted documents.

For example, many teachers of our sample listen to the radio, and particularly a national cultural channel to acquire information resources. They also frequently use design websites or print media. Elisa says that she frequently consults a dozen of sites, she calls "sanctuaries". Gwennaelle uses the same consultation scenario to check the relevance of students' issues.

Furthermore, many teachers rely on their human network as a preferential source. For instance, Renaud relies on his network of friends that includes long-term relationships with people with common interests. His network brings him recent information related to his research activities that he reinjects partly in his teaching activities. These relationships lead him to cultivate a reciprocal collaborative environmental scanning. He provides fresh and grey information resources back to his network.

Finally, the renewal leverages online and human pillars that provide new valuable information that can become resources.

\subsection{Valuable information resources}

Teachers define valuable information resources as pedagogically relevant information that can be shared at a large scale with many students. They generally store valuable resources over a long-time span.

Yohann: "valuable contents that are pedagogically very useful, very meaningful [...] something that I consider to be potentially interesting, for specific lesson situation, generally, I download it and I store it." 
Teachers also look for emergent themes rooted in reality. Those themes come from fresh and grey information obtained for some of them through their networks. They use their networks to access them.

Johann: "The Intel engineer finally here is really on a start-up logic, so he is really on this

dynamic of innovative start-up, on the lookout for emergent themes, so he provides us with a lot." Therefore, we notice two rhythms of renewal, a long run renewal to accumulate and a quick renewal to be aware of the latest trends. Networking plays a central role in acquiring grey and fresh information.

\subsection{Untapped information resources}

Our results show that during their environmental scanning, teachers identify what we call untapped territories that open up new design opportunities. Every teacher qualifies a wasteland according to his own filters. This wasteland is for some teachers primarily based on the physical proximity of the scanning environment.

Tristan: "objects that have not necessarily been seen by designers" or "objects that everyone uses but nobody pays attention to."

For other teachers, this wasteland is filled with "emerging issues" that can "make sense for a designer tomorrow" (Johann), and "something that is really contemporary, not necessarily precursor but that can anticipate a small practice, emerging uses or changes in the society or that may not be fully enrolled yet but will be working on it" (Yohann).

Resource renewal is daily, teachers observe their environment for ideas to feed their topics and to support students.

\subsection{The planning seasonality}

Teachers try to anticipate the needs regarding the design of topics and students support. They practice an uninterrupted environmental scanning by buffering information resources from collaborative work with their colleagues, partners and students.

Elisa: "We are a teacher 24 hours a day. The desire for things is no longer a job. I saw this information in a magazine, and I thought that it could be a very interesting thing for a student. I stored it somewhere in my head, I cannot tell you exactly where. And when this student was in trouble, I recalled this wood factory, so I told her about it."

A higher scanning activity is observed during topic design, we notice a stronger activity before the beginning of the lessons.

Renaud "we have to renew, we could almost say that each student group has a backlog of projects".

Renewal is permanent and relies on academic rhythm and duration. Design of topics with colleagues and partners also affect the rhythm of resource acquisition and renewal because teachers must be ready to bring creative incentive ideas.

\section{DISCUSSION AND PERSPECTIVES}

Our results show that teachers' motivation for resource renewal are oriented mainly in two directions. First, teachers are focused on their own area of interest, to feed the design of project topics. Second, teachers concentrate on students' areas of interest for pedagogical support.

Teachers show very personal problem areas for resource acquisition. Yet, pedagogical requirements influence teacher scanning renewal according to whether they define topic projects, whether they cobuilt them with colleagues and partners and whether they rely on external sources such as contests or sponsors.

Teachers have preferential sources, displaying specific of which they show consultation habits. They maintain reciprocal scanning relations with their network. They outsource their environmental scanning through their personal circles, sending them adapted information and receiving in return emerging issues and professional inputs. This is in line with the importance of the networking that was previously underlined. The network is often used as a preferential source to access valuable information.

Students can also be a preferential source. Their work becomes a recurrent source of acquisition and renewal for teachers. Human sources are central to resource renewal. 
The renewal rhythm and planning are related to pedagogical temporalities. Monitoring effort are modulated according to the periods and the interactions with the actors of the pedagogical contexts. Furthermore, teachers have anticipatory behaviors in order to assume the time constraints of the design of topics and the support of students' needs.

They exhibit outsourcing strategies to renew their resources in a sustainable way.

Our results highlight the complexity of teachers' activities and renewal strategies. Teachers evolve in a complex environment and a network of digital and human sources. They follow singular scenarios in which human, analog and digital sources intersect to provide up to date resources. Environmental scanning maintains their awareness to contemporary design issues all the while supporting the renewal of resources.

We observe that teachers provide other courses beyond design studios. Our future work will study the impact of other courses on the renewal processes and the nature of collected resources. This open up a reflection on the management of resources at a team level.

\section{REFERENCES}

Albright, K. (2004), "Environmental scanning: radar for success", The Information management journal. Vol. 38 No. 3, pp. 38-45.

Amabile, S. (1999), "De la veille stratégique a une attention réticulée. Le réseau d'attention inter-organisationnel des mutuelles d'assurance automobile", Revues Systèmes d'Information et Management, Vol. 4 No. 2, pp. 19-37, Ed. ESKA. http://dx.doi.org/10.9876/ sim.v4i2.60

ANR-ReVEA report/ Gueudet, G. (2015), Livrable 3-1, Paris, France.

ANR-ReVEA report/ Loffreda, M., Bruillard (2017), Modes de circulation des ressources éducatives et en particulier des REL: Choix et conception de ressources par les enseignants, Paris, France.

Ansoff, H. I. (1984), Implanting strategic management. Prentice Hall, Englewood Cliffs, NJ. https://doi.org/10.1007/978-3-319-99599-1

Archer B., Bayne K. and Roberts P. (1992), The nature of research into Design and Technology education. Design Curriculum Matters. Department of design technology. Loughborough, Loughborough. University. https://dspace.lboro.ac.uk/2134/1687

Ashton, P. (2007), "Transferring and transforming design knowledge", Proceedings of the Experiential Knowledge Conference, Hatfield, Hertfordshire, UK.

Bhardwaj, S.S, Kumar, D. (2014), "Environmental scanning by fmcg companies in india: a comparative study", International Journal of Management end International Business Studies. Vol. 4 No. 1, pp. 39-50.

Boya, (2010), "Note théorique sur la quantification du besoin informatif en Intelligence Économique", Revue internationale d'intelligence économique, No. 2, pp.191-199.

Breillat J. (2011), "Réseaux: la force des liens faibles, Blog Intelligence économique", Information et Influence. http://jacques.breillat.fr/lobbying_desinformation/reseaux-la-force-des-liens-faibles (consulted the 30-082018).

Broadbent J.A. and Cross N. (2003), "Design education in the information age", Journal of Engineering Design, Vol. 14 No. 4, pp.439-446. https://doi.org/10.1080/09544820310001606867

Chen, W. (2016), "Exploring the learning problems and resource usage of undergraduate industrial design students in design studio courses", International Journal of Technology and design. Vol. 26 No. 3, pp.:461-487. http://doi.dx.org/10.1007/s10798-015-9315-2

Brown, A., Wiener, E. (1985), Supermanaging: How to harness change for personaI and organizational success. Mentor, New York.

Choo, C.W. (1999), "The art of scanning the environment", Bulletin of the American Society for Information Science and Technology. Vol. 25 No. 3, pp. 21-24. https://doi.org/10.1002/bult.117.

Daft, R.L., Sormunen, J. and Parks, D. (1988), "Chief executive scanning, environmental characteristics, and company performance: an empirical study", Strategic Management Journal. Vol. 9 No. 2, pp. 123-139. https://doi.org/10.1002/smj.4250090204

Debs, L., Kelley, T. (2015), "Gathering Design References from Nature”, Technology and engineering teacher. pp. $10-14$.

Deiss, J. (2015), L'art de faire des recherches et de partager l'information, FYP Édition.

Demirbas, O. O., Demrikan H. (2007), "Learning styles of design students and the relationship of academic performance and gender in design education", Learning and Instruction. Vol. 17 No. 3, pp. 345-359. http://doi.dx.org/10.1016/j.learninstruc.2007.02.007

Duncan, R.B. (1972), "Characteristic of Organizational Environments and Perceived Environment Uncertainty", Administrative science quaterly, pp. 17-313. https://doi.org/10.2307/2392145

Fahey, L., King, R. and Narayanan, V.K. (1981), "Environmental Scanning and Forecasting in Strategic Planning", Long range planning. Vol. 14, No. 1, pp. 14-8. https://doi.org/10.1016/0024-6301(81)90148-5. 
Geel, C. (2010), "Le designer à l'aune de la créativité”, Mode de recherche, n 14, Assouly O. (dir), Institut Francais de la Mode, juin 2010, pp. 32-40.

Goncalves M., Cardoso C., Badke-Schaub P. (2014), "Inspiration choices that matter: the selection of external stimuli during ideation", Design science. Vol. 2. https://doi.org/10.1017/dsj.2016.10

Granovetter M.S. (1973), “The strength of weak ties”, American. Journal of Sociology. Vol. 78 No. 6, pp. 13601380. https://doi.org/10.1086/225469

Haase, H. and Franco, M. (2011), "Information sources for environmental scanning: do industry and firm size matter?”, Management Decision. Vol. 49 No. 10, pp. 1642-1657. https://doi.org/10.1108/00251741111183807.

Hambrick, D.C. (1982), "Environmental scanning and organizational strategy", Strategic Management Journal. Vol. 3 No. 2, pp. 159-174. https://doi.org/10.1002/smj.4250030207

Hiltunen, E. (2006), "Was it a wild card or just our blindness to gradual change?", Journal of future studies Vol. 11 No. 2, pp. 61-74. https://doi.org/10.6531/JFS.2018.22(3)

Hiltunen, E. (2008), "Good sources of weak signals: a global study of where futurists look for weak signals", Journal of future studies. Vol. 12 No. 4, pp. 21-44.

citeseerx.ist.psu.edu/viewdoc/summary?doi=10.1.1.390.9014

Huber G. P. (1998), "Synergies between Organizational Learning and Creativity and Innovation", Organizational learning and creativity \& innovation journal. Vol. 7 No. 1, pp. 3-8. https://doi.org/10.1111/1467-8691.00079

Huberman et Miles, (1991), Analyse de données qualitatives: recueil de nouvelles méthodes. De Boek-Wesmael, Bruxelles.

Hurtado, A. (2014), Aide à la prise de décision stratégique. Détection de données pertinentes de sources numériques sur Internet. Grenoble, $\mathrm{PhD}$ thesis in management sciences under the direction of M-L. CARON-FASAN, Grenoble, Université de Grenoble.

Jain, S.C. (1984), "Environmental scanning in U.S. corporations”, Long Range Planning. Vol. 17 No. 2, pp.117128. https://doi.org/10.1016/0024-6301(84)90143-2

Javidan, M. (1984), "Research note and communication. The impact of environmental uncertainty on long-range planning practices of the U.S. savings and loan industry", Strategic Management Journal. Vol. 5 No. 4, pp. 381-392. https://doi.org/10.1002/smj.4250050407.

Jouvenel, Désaunay et Grzesiak, (2016), Rapport Vigie 2016, Futurs possibles à l'horizon 2030-2050, Futuribles International, Paris.

Keegan, W.J. (1974), "Multinational scanning: a study of the information sources utilized by headquarters executives in multinational companies”, Administrative Science Quarterly. Vol. 19 No. 3 on p. 411. https://doi.org/10.2307/2391981

Morrison, J. L. (1992), “Environmental scanning”, In M. A. Whitely, J. D. Porter and R. H. Fenske (Eds.), A primer for new institutional researchers, pp. 86-99.

O’Connor E., (2005), "Embodied knowledge”, Ethnography. Vol. 6 No. 2, pp. 183-204. https://doi.org/10.1177/1466138105057551

Paquay, L. (2006), "Introduction. Au-delà des cloisonnements entre divers types de recherche, quels critères de qualité?”, in Léopold Paquay et al., L'analyse qualitative en éducation, De Boeck Supérieur « Pédagogies en développement », pp. 13-29.

Quarante D., (1981), "L’expérience de Compiègne”, pp. 156-161.

Robinson, C.V., and Simmons, J.E.L. (2017), "Organizing environmental scanning: Exploring information source, mode and the impact of firm size", Long Range Planning. Vol. 51 No. 4, pp. 526-539. https://doi.org/10.1016/j.lrp.2017.10.004

Schoemaker, P.J.H., Day, G.S., and Snyder, S.A. (2012), "Integrating organizational networks, weak signals, strategic radars and scenario planning". Technological Forecasting and Social Change. Vol. 80 No. 4, pp. 815-824. https://doi.org/10.1016/j.techfore.2012.10.020

Schöpfel, J. (2015), “Comprendre la littérature grise”, I2D - Information, données \& documents. 2015/1, Vol. 52 , pp. 30-32.

Smith, J., Cook, A., and Packer, C. (2010), "Evaluation criteria to assess the value of identification sources for horizon scanning", International Journal of Technology Assessment. Vol. 26 No. 3, pp. 348-353. https://doi.org/10.1017/s026646231000036x

Strickfaden, M., Heylighen, A., Rodgers, P., Neuckermans, H. (2006), "Untangling the culture medium of students designers", Codesign. Vol. 2 No. 02, pp. 97-107. https://doi.org/10.1080/15710880600647980

Strickfaden, M., Heylighen, A. (2010), "Cultural capital: a thesaurus for teaching design", International Journal of Arts \& Design Education. Vol. 29 No. 2, pp. 121-133. https://doi.org/10.1111/j.14768070.2010.01653.x

Strickfaden, M., Rogers, A. (2007), "References in the design process", International Conference on Engineering Design. Cité des Sciences et de 1'Industrie, Paris, France. ICED’07, pp. 1-12. 
Woudstra, L. and Van den Hooff, B. (2008), "Inside the sources selection process: selection criteria for human information sources", Information Processing \& Management. Vol. 44 No. 3, pp. 1267-1278. https://doi.org/10.1016/j.ipm.2007.07.004

Yoo, S., Sawyerr, O. (2014), "The search for broad environmental information and new product development success in technology-based SMES”, Journal of Enterprising Culture, Vol. 22, pp. 27-55. https://doi.org/10.1142/s0218495814500022 